\title{
A rare complication of leptospirosis: acute pancreatitis
}

\section{HMM Prasanthie ${ }^{1}$, KHPUD De Silva ${ }^{2}$}

${ }^{1}$ Registrar in Medicine, ${ }^{2}$ Consultant Physician, Teaching Hospital Karapitiya, Galle.

\section{Introduction}

Leptospirosis is an acute and often severe infection that frequently affects the liver or other organs and is caused by Leptospira icterohaemorrhagiae, mainly the rat borne variety ${ }^{1}$. A definite relationship has been established between leptospirosis and paddy cultivation because of contamination of water in paddy fields by rat excreta. Sporadic urban cases have been seen in the homeless exposed to rat urine ${ }^{1}$.
The IgM EIA is particularly useful in making an early diagnosis, since it is positive as early as two days into the illness and is extremely sensitive and specific ${ }^{2}$. Major complications of leptospirosis are renal failure, liver failure, myocarditis, aseptic meningitis. Rare complications are pulmonary infiltrates with haemorrhage, acute pancreatitis and iridocyclitis ${ }^{1}$. Penicillin, ceftriaxone and Tetracyclines are effective in the treatment and doxycycline once weekly during the risk of exposure is used in prophylaxis ${ }^{1}$. 


\section{Case report}

A 28 year-old male presented with fever for three days. The fever was associated with myalgia and vomiting. His urine output was normal. Two weeks prior to the febrile illness he worked in a paddy field. He smokes occasionally and does not consume alcohol.

On examination he was icteric and was found to have conjunctival suffusion and a diffuse abdominal tenderness. The pulse rate was 100 bpm and his blood pressure was 90/70 $\mathrm{mmHg}$. Clinically he was diagnosed as suffering from leptospirosis and treatment was commenced with intravenous (IV) penicillin. On the second day following admission he complained of sudden onset severe upper abdominal pain radiating to the back associated with nausea, vomiting and sweating. A reduction in his urine output was noted. On examination patient was found to have, hypotension, severe abdominal tenderness absent bowel sounds and his breathing was acidotic.

\section{Investigations}

The total WBC was $13,000 / \mathrm{mm}^{3}$ with $92 \%$ neutrophils and the platelet count was 50,000 / $\mathrm{mm}^{3}$. The subsequent platelet count was 16000 $/ \mathrm{mm}^{3}$. Urine full report revealed pus cells $1-2$ /f and red cells 20-25 /f. The blood urea was 142 $\mathrm{mg} / \mathrm{dL}$, serum $\mathrm{Na}^{+}$was $138 \mathrm{mmol} / \mathrm{L}$ and $\mathrm{K}^{+}$was $3.3 \mathrm{mmol} / \mathrm{L}$, respectively.

The serum creatinine was $3.3 \mathrm{mg} / \mathrm{dL}$ and the creatinine phosphokinase was 273 U/L. Leptospira IgM antibody was positive. Liver function test revealed serum bilirubin of 221 $\mathrm{mmol} / \mathrm{L}$, SGOT of $106 \mathrm{U} / \mathrm{L}$, SGPT $60 \mathrm{u} / \mathrm{L}$ and serum amylase of $1834 \mathrm{U} / \mathrm{L}$. Serum triglycerides was $198 \mathrm{mg} / \mathrm{dL}$. Serum calcium was $7.6 \mathrm{mg} / \mathrm{dl}$ with normal albumin. Arterial blood gas showed $\mathrm{PH}$ of 7.3 with bicarbonate of $15.4 \mathrm{mmol} / \mathrm{L}$.

The above findings were compatible with leptospirosis with acute pancreatitis. The patient was treated with IV fluids, IV penicillin, inotropes, calcium gluconate, sodium bicarbonate and a platelet transfusion was also given. He recovered completely.

\section{Discussion}

Acute pancreatitis can be suspected clinically, but requires biochemical and radiologic and sometimes histologic evidence to confirm the diagnosis. All the above features need to be considered together since none of them alone is diagnostic of acute pancreatitis ${ }^{3}$.

Clinical features are upper abdominal pain radiating to back with nausea, vomiting and epigastric tenderness. Grey turners and Cullen signs are bad prognostic signs of acute pancreatitis.

Biochemical findings of acute pancreatitis include an increased serum and urinary levels of enzymatic and nonenzymatic pancreatic secretions. Among them amylase and lipase are important. Serum amylase rises 2 to 12 hours from the onset of symptoms and normalizes within 48 to 72 hours. Serum lipase rises 4 to 8 hours from the onset of symptoms and normalizes within 7 to 14 days ${ }^{4}$.

The most common causes of pancreatitis are alcohol, gallstones, mumps, hypercalcaemia, hypertriglyceridemia, autoimmune diseases and drugs. Less common causes are bacterial infection (Leptospirosis, Mycoplasma infection, Salmonellosis), viral infection (Varicella zoster, Herpes simplex), mycoses (aspergillus), Parasitic infection (Ascaris, Toxoplasmosis), repeated marathon running and pregnancy ${ }^{3}$.

This case report highlights the need to be aware of common illnesses that can have rare complications like leptospirosis and acute pancreatitis.

\section{References}

1. Kobayashi Y. Human leptospirosis. Management and prognosis. Journal of Postgraduate Medicine 2005; 51: 201.

2. Ahmad SN et al: Laboratory diagnosis of leptospirosis. Journal of Postgraduate Medicine 2005; 51: 195. [PMID :16333192]

3. Opic EL. The etiology of acute hemorrhagic pancreatitis. Bull Johns Hopkins Hosp. 1991; 12: 182.

4. Banks P, Freeman M. Practice guidelines in acute pancreatitis. Am J Gasroenterol 2006; 101: 2379-400. 